\title{
Investigation of Primary Recovery in Low-Permeability Oil Formations: A Look at the Cardium Formation, Alberta (Canada)
}

\author{
S.M. Ghaderi*, C.R. Clarkson and D. Kaviani \\ Department of Chemical and Petroleum Engineering, University of Calgary, 2500 University Drive N.W., Calgary, Alberta - Canada \\ e-mail: smghader@ucalgary.ca - clarksoc@ucalgary.ca -dkaviani@ucalgary.ca \\ * Corresponding author
}

\begin{abstract}
Résumé - Recherches sur la récupération primaire dans les formations de pétrole de faible perméabilité : étude de la formation de Cardium, Alberta (Canada) - Les formations compactes de pétrole (perméabilité $<1 \mathrm{mD}$ ) dans l'Ouest canadien sont récemment apparues comme étant une ressource sûre d'approvisionnement en pétrole léger en raison de l'utilisation de puits horizontaux multifracturés. La formation de Cardium, qui contient $25 \%$ du total de pétrole léger découvert dans l'Alberta (selon l'Alberta Energy Resources Conservation Board), comprend des zones de production conventionnelles et non conventionnelles (de faible perméabilité ou compacts). Les zones de type conventionnel ont été développées dès 1957. En revanche, le développement des zones de type non conventionnel représente un événement récent à cause des propriétés considérablement moins bonnes des réservoirs, ce qui augmente le risque lié au placement de capitaux. Cela implique donc la nécessité d'une étude globale et critique de la zone avant de prévoir toute stratégie de développement.

Cet article présente des résultats à propos de la performance des portions de faible perméabilité de la formation de Cardium où de nouveaux puits horizontaux ont été forés et stimulés en multiples étapes afin de favoriser des fractures hydrauliques transversales. Le développement de la formation compacte de Cardium au moyen d'une récupération primaire est envisagé. Les données de production de ces puits ont d'abord été recréées à l'aide d'un simulateur d'écoulement. Le modèle calibré a été utilisé pour prédire les performances en production à partir d'analyses de sensibilité par rapport à différents paramètres dont des facteurs de conception comme l'espacement des puits, les propriétés des fractures et les contraintes opératoires.
\end{abstract}

\footnotetext{
Abstract - Investigation of Primary Recovery in Low-Permeability Oil Formations: A Look at the Cardium Formation, Alberta (Canada) - Tight oil formations (permeability $<1 \mathrm{mD}$ ) in Western Canada have recently emerged as a reliable resource of light oil supply owing to the use of multifractured horizontal wells. The Cardium formation, which contains $25 \%$ of Alberta's total discovered light oil (according to Alberta Energy Resources Conservation Board), consists of conventional and unconventional (low-permeability or tight) play areas. The conventional play areas have been developed since 1957. Contrarily, the development of unconventional play is a recent event, due to considerably poorer reservoir properties which increases the risk associated with capital investment. This in turn implies the need for a comprehensive and critical study of the area before planning any development strategy.
} 
This paper presents performance results from the low permeability portions of the Cardium formation where new horizontal wells have been drilled and stimulated in multiple stages to promote transverse hydraulic fractures. Development of the tight Cardium formation using primary recovery is considered. The production data of these wells was first matched using a black oil simulator. The calibrated model presented was used for performance perditions based on sensitivity studies and investigations that encompassed design factors such as well spacing, fracture properties and operational constraints.

\section{NOMENCLATURE}

$F_{c d} \quad$ Fracture conductivity (dimensionless)

$k \quad$ Matrix permeability, $L^{2}(\mathrm{mD})$

$k_{f} \quad$ Permeability of hydraulic fracture, $L^{2}(\mathrm{mD})$

$k_{f}^{\prime} \quad$ Permeability of hydraulic fracture in simulation model, $L^{2}(\mathrm{mD})$

$n \quad$ Dimensionless well length

$p_{b} \quad$ Bubble point pressure $\left(\mathrm{m} / \mathrm{Lt}^{2}\right)(\mathrm{psi})$

$p_{w f} \quad$ Well flowing pressure $\left(\mathrm{m} / \mathrm{Lt}^{2}\right)(\mathrm{psi})$

$w_{f} \quad$ Fracture width $L(\mathrm{ft})$

$x_{f} \quad$ Fracture half length $L(\mathrm{ft})$

\section{Greek symbols}

$\Delta_{f} \quad$ Equivalent fracture width in the simulation model, $L(\mathrm{ft})$

\section{SI CONVERSION FACTORS}

acre $\times$ 4.046873.E-03 $=\mathrm{m}^{2}$

$\mathrm{bbl} \times 1.589873 . \mathrm{E}-01=\mathrm{m}^{2}$

$\mathrm{cp} \times 1.0^{*} . \mathrm{E}-03=$ Pa.s

$\mathrm{ft} \times 3.048^{*} . \mathrm{E}-01=\mathrm{M}$

$\mathrm{lbm} \times 4.53592 . \mathrm{E}-01=\mathrm{kg}$

$\mathrm{mD} \times 9.869223 . \mathrm{E}-16=\mathrm{m}^{2}$

$\mathrm{psi} \times 6.894757 . \mathrm{E}+03=\mathrm{Pa}$

* Conversion factors are exact.

\section{INTRODUCTION}

Economic production of hydrocarbons from reservoir rocks requires reservoir-specific solutions. Until recently, oil and gas exploitation was restricted to relatively high permeability and porosity reservoirs. In such reservoirs, wellbore contact through vertical wells was sufficient to obtain economic rates and recovery. Recent advances in drilling and completion technology have enabled commercial production from reservoirs with poorer properties. The low-permeability area of the
Pembina Cardium field in Western Canada, referred to as a "Halo Oil" play by Clarkson and Pedersen (2011), is an example.

The Pembina Cardium field is the principal conventional oil pool in Canada covering an area of over $3000 \mathrm{~km}^{2}$ with more than 6100 wells (approximately 4400 producers and 1700 injectors which are mainly vertical). Original oil in place is in excess of $7780 \mathrm{MMbbl}$ with recovery of less than $17 \%$ to date. The field is located in a stratigraphic trap of northwest-southeast oriented shoreface sands with the eastern up-dip margin being defined by shale out of the sands and the western downdip margin by decreasing reservoir quality (Krause et al., 1987). Horizontal wells have been drilled in both the Cardium sands and conglomerates within the Pembina field with limited success (Adegbesan et al., 1996).

In 2008, the first horizontal well with seven hydraulic fracture stages was completed in the unconventional (low-permeability) portion of the Cardium. The production rates from this well were so promising (average production rates of approximately $123 \mathrm{bbl} /$ day without any water production) that another 12 wells were drilled in 2009 (Viau and Nielsen, 2010). Since then, more and more multi-fractured horizontal wells are being completed or planned in the area by different companies.

Because the unconventional portion of the Pembina is at early stages of production and development, more detailed studies are required for better management and exploitation of the resources. In this study, our purpose is to determine the major parameters that will affect the recovery of oil from these reservoirs under primary production scheme when fractured horizontal wells are being used. Oil production rates from the wells are usually high at the beginning, nevertheless limited permeability of the bulk of reservoir impede favorable rates over the long term. Therefore short-term and long-term production performance will be considered separately in this work. As part of the study, extensive numerical simulations were performed using the ECLIPSE $100^{\mathrm{TM}}$ simulator $^{(1)}$ (Schlumberger, 2010). The Design of Experiment (DOE) approach was employed to define the simulation

\footnotetext{
${ }^{1}$ ECLIPSE 100, ECLIPSE and PVTi are trademarks of Schlumberger.
} 
scenarios and the parameters involved. In each simulation run, several parameters can be varied simultaneously to capture the effect of all main parameters and their likelihood of interaction. The oil recovery from simulation runs will be the main response in the statistical interpretation of the results. Simulation strategies and results will first be discussed.

\section{BASE PROPERTIES USED IN SIMULATION MODELS}

The properties required for generating simulation models were obtained from one of the active operators in the area. To avoid issues related to reservoir heterogeneity, all reservoir properties are considered constant at their average values. Some of these properties are summarized in Table 1 (modified from Clarkson and Pedersen, 2010). The data in this table have been obtained from an area of Cardium where the pay zone varies between 16 to $26 \mathrm{ft}$ and the reservoir rock consists of muddy fine-grained sandstones with low permeability $(\approx 0.3 \mathrm{mD})$ but relatively suitable porosity $(\approx 0.12)$. It is also known that the reservoir is not supported by any initial gas cap (note the initial reservoir pressure and oil bubble point pressure in Tab. 1,2) or bottom water support and therefore the main mechanism of primary production would be through solution gas drive (Clarkson and Pedersen, 2010).

Table 2 provides the fluid data used in the simulation models which are based on the real data obtained from one of the wells in the study area. The oil is relatively light with ${ }^{\circ}$ API equal to 37 . Figure 1 depicts the results obtained from the simulation of the PVT data for oil and gas using the $\mathrm{PVTi}^{\mathrm{TM}}$ module of Eclipse (Schlumberger, 2010). Figures 1a, b show the results of the differential liberation test and the viscosity measurements (Fig. 1c, d) obtained from constant composition expansion test. Pedersen's correlation (Pedersen et al., 1984) was used to match the viscosity data. For the range of pressure applicable to this study (200-2 000 psia), the match of the PVT data is acceptable. The results of Table 2 are similar to what was used by Clarkson and Pedersen (2010) using standard correlations.

One missing element in our simulation models was a relative permeability data set. To obtain the relative permeability or at least a rough estimate of its shape, we tried to history match the production data of the wells in the study area and used the relative permeability data as the matching parameter. We received about one year production data for three separate wells in the region from an operator. For the well selected for analysis, the pressure is somewhat less than the virgin pressure (approximately $2500 \mathrm{psi}$ ), suggesting that some
TABLE 1

General properties of the simulation models

\begin{tabular}{c|c}
\hline Simulation model parameter & Parameter value \\
\hline Thickness (ft) & 16.4 \\
\hline Porosity (\%) & 12 \\
\hline Absolute permeability (mD) & 0.28 \\
\hline Initial reservoir pressure (psia) & 2017 \\
\hline Initial oil saturation $(\%)$ & 86 \\
\hline Initial water saturation $(\%)$ & 14 \\
\hline Reservoir temperature $\left({ }^{\circ} \mathrm{F}\right)$ & 115 \\
\hline $\begin{array}{c}\text { Model area (acres) } \\
\text { Number of blocks } \\
(N X \times N Y \times N Z)\end{array}$ & 640 \\
\hline $\begin{array}{c}\text { Dimension of blocks } \\
(\mathrm{ft} \times \mathrm{ft} \times \mathrm{ft})\end{array}$ & $50 \times 50 \times 16.4$ \\
\hline
\end{tabular}

TABLE 2

Fluid properties used in the simulations

\begin{tabular}{c|c}
\hline Oil & \\
\hline$P b(\mathrm{psia})$ & 1602 \\
\hline$R s$ at $P b(\mathrm{scf} / \mathrm{stb})$ & 430 \\
\hline Viscosity at $P b(\mathrm{cp})$ & 1.43 \\
\hline$B o$ at $P b(\mathrm{res} . \mathrm{bbl} / \mathrm{stb})$ & 1.22 \\
\hline Density at STP $\left(\mathrm{lbm} / \mathrm{ft}^{3}\right)$ & 51.8 \\
\hline Gas & 0.011 \\
\hline Ave. Viscosity $(\mathrm{cp})$ & 0.069 \\
\hline Density at STP $\left(\mathrm{lbm} / \mathrm{ft}^{3}\right)$ & \\
\hline Water & 0.58 \\
\hline Viscosity $(\mathrm{cp})$ & \\
\hline
\end{tabular}

depletion due to offsetting vertical wells may have occurred. Nonetheless, we analyzed the well individually, realizing that a field simulation may be justified.

Well completion data were obtained from the operator. The length of the horizontal well is $3865 \mathrm{ft}$ and its wellbore diameter is 7.2 inches. It was frac'd in 10 stages with an average fracture spacing of $429 \mathrm{ft}$ (assuming 1 fracture per stage). We estimate the fracture halflength to be equal to $181 \mathrm{ft}$ and fracture conductivity close to $300 \mathrm{md}-\mathrm{ft}$. The well is completed open-hole (Clarkson and Pedersen, 2010). 

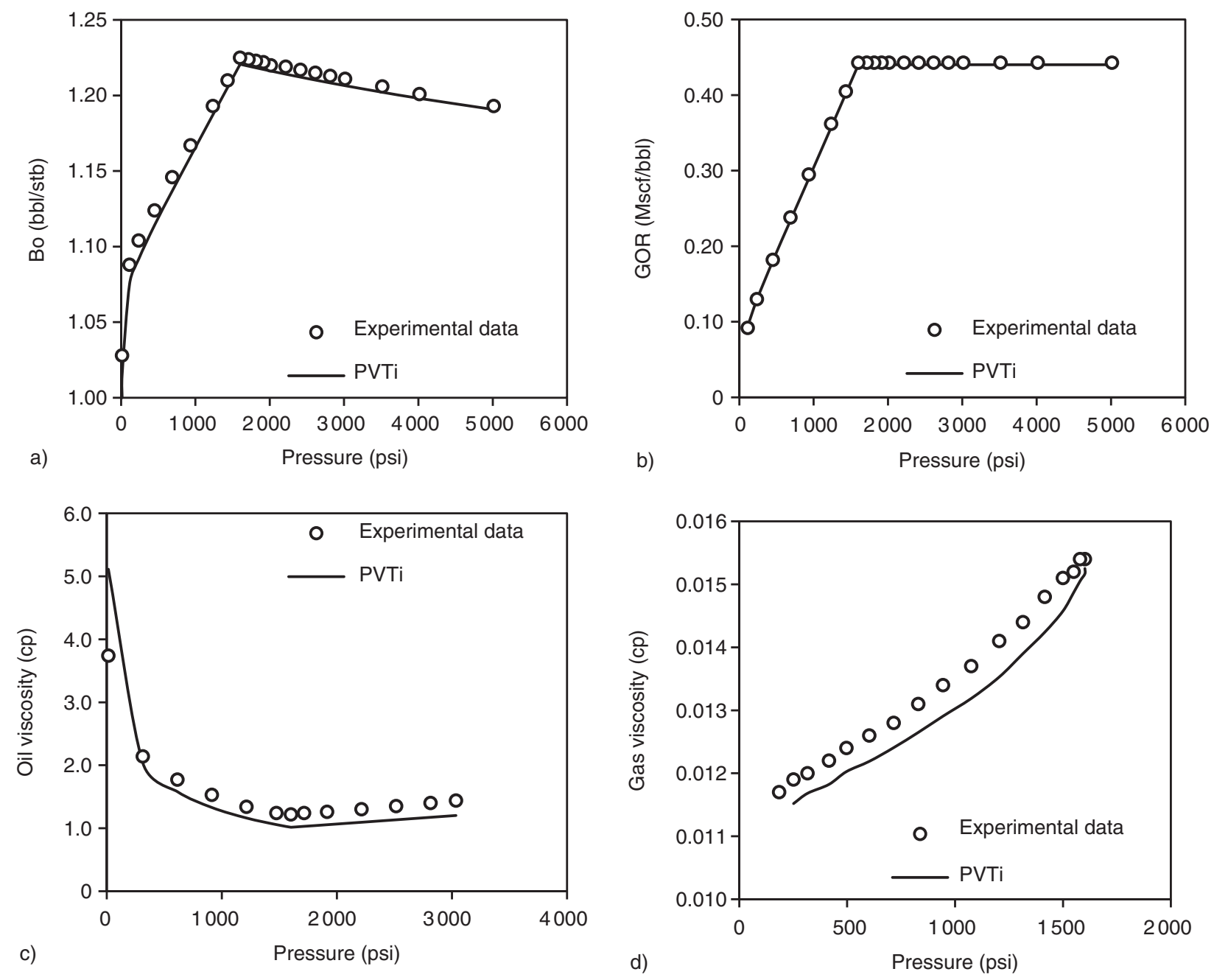

Figure 1

Comparison between the experimental and simulated PVT behavior of the fluid used in this study: a) oil formation volume factor $v s$ pressure, b) oil solution gas $v s$ pressure, c) oil viscosity $v s$ pressure, d) gas viscosity $v s$. pressure.

Figure 2a displays a close-up view of the simulated transverse fractures planes which are perpendicular to the well trajectory. To precisely capture the physics of the fluid flow in the models, the Local Grid Refinement (LGR) feature is used to explicitly construct the hydraulic fractures along the well. However, exact duplication of the fractures' width in a simulation model will require extremely refined grids which results in computationally very expensive models (Shaoul et al., 2007). Therefore, a sensitivity study was performed to determine the optimal degree of refinement for the fractures blocks as well as the parent block dimensions. Also, transmissibility of the fractures blocks should be adjusted such that following relationship holds:

$$
k_{f} \times w_{f}=k_{f}^{\prime} \times \Delta_{f}
$$

where $k_{f} \times w_{f}$ is the product of fracture permeability and width and $k_{f}^{\prime} \times \Delta_{f}$ is the corresponding product in the simulation model. The hydraulic fractures in our study have a constant width equal to $2.0 \mathrm{ft}$ which are obtained by dividing the parent grid block into 25 parts in the direction perpendicular to the fracture orientation.

Figure $2 b$ shows the historic oil production rates from the subject well for almost one year. It should be noted that in Figure 2 time zero corresponds to the time when the well has reached the "pump-off state", signified by a stabilized fluid level in the annulus. As the well bottomhole pressure (BHP) was estimated from periodic fluid 
a)
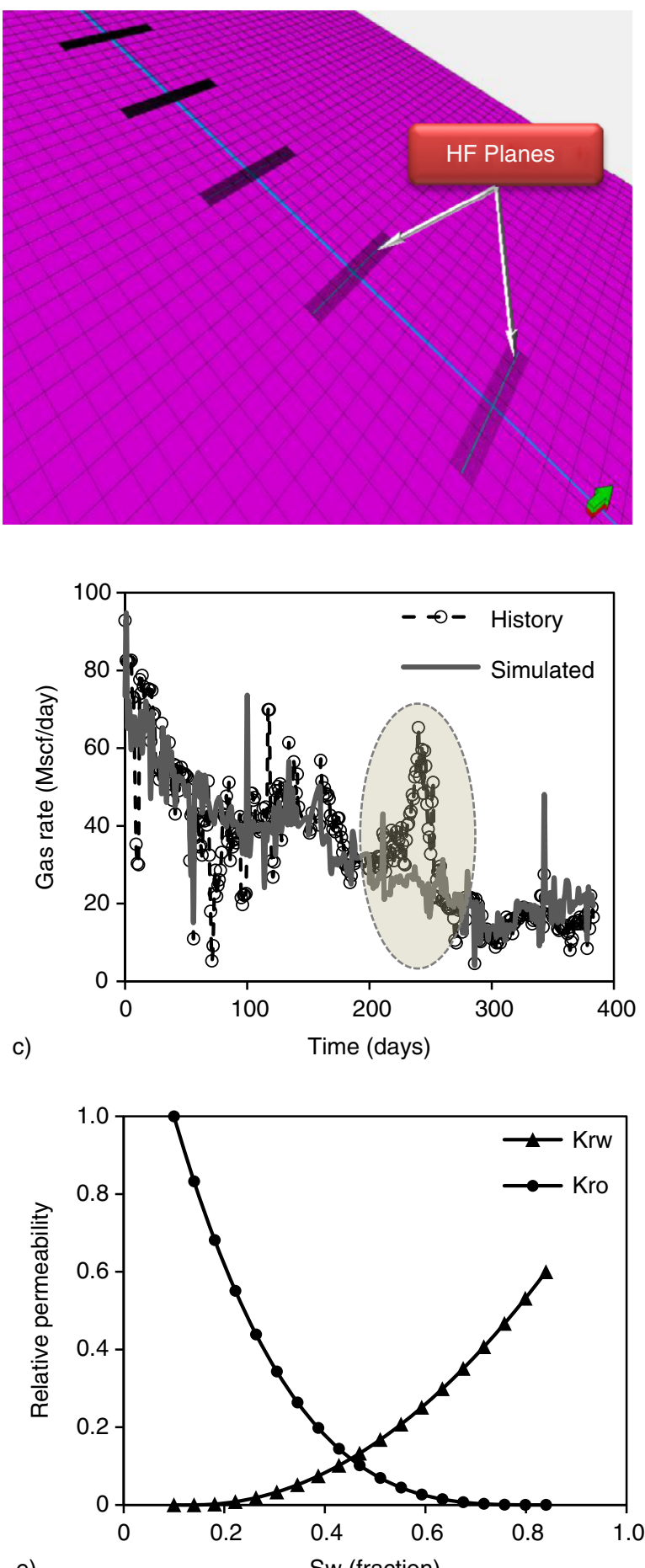

e)

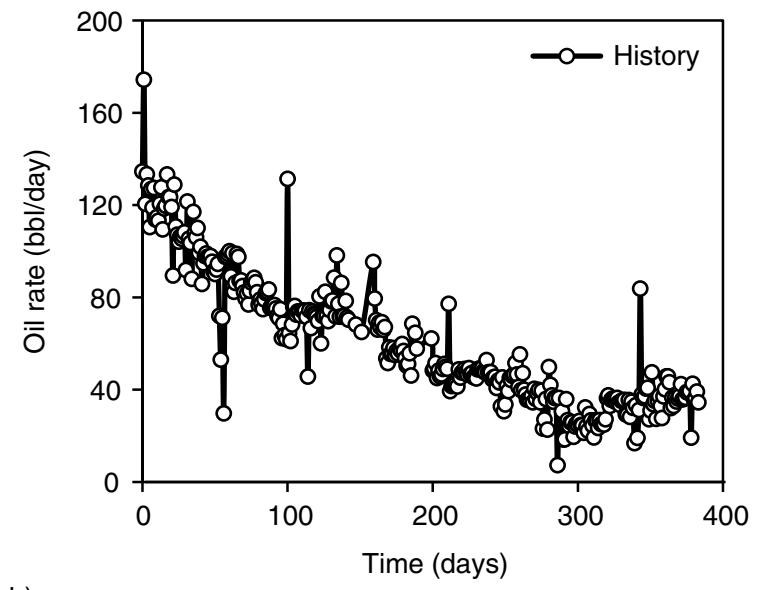

b)
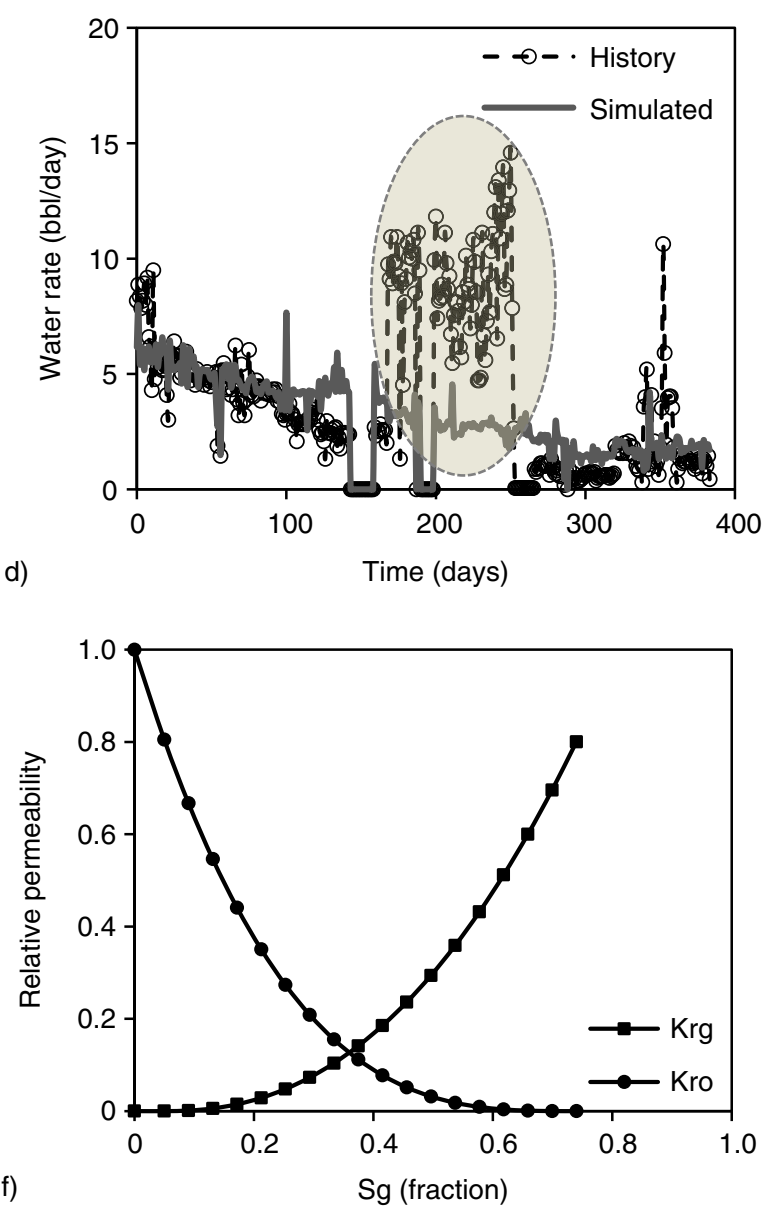

Figure 2

a) A close-up view of the simulation model showing the fractures' plane crossing the well lateral; b) historical oil production data for the subject well; c-d) comparison of gas and water production data from well history and simulation, respectively; e-f) two-phase relative permeability of water-oil and gas-oil obtained from history matching of production data, respectively. 
shots combined with casing pressure, a stabilized fluid level in the annulus indicates that the well is producing under constant BHP. For the period of production displayed in Figure $2 \mathrm{~b}$ this BHP is close to 250 psia (the pressure data is not shown).

For history-matching, oil production rate and flowing pressure were honored in the simulator and gas and water production rates were predicted. Figure $2 \mathrm{c}$ shows the gas production history from the well and the simulation results from the history-matching process, while Figure $2 \mathrm{~d}$ shows the water production rate match. Although the overall match in both graphs looks acceptable and the trends are honored, there is a period (between 185 to 240 days) in which the simulation results are quite different from the historical data. The anomalous well production during this period is due to an unknown operational change in the well and is ignored in the simulation model.

Figures $2 \mathrm{e}, \mathrm{f}$ show the two phase water-oil and gasoil relative permeability curves which were obtained as a result of history-matching the production data. The curves were generated with the Corey correlation for initial simulations. These were then adjusted for matching historical water and gas rate measurements. It is important to note that because the changes in the gas rate follow the changes in the oil rate (compare Fig. $2 b, c)$ and also the gas rate has stabilized at the end of the matching period, the reservoir is interpreted to be above the bubble point pressure (if the pressure falls below the bubble point pressure we will experience a sharp increase in gas rate and consequently gas-oil ratio). As also noted by Clarkson and Pedersen (2011), the GOR is relatively flat through the production history. Therefore, because only oil and water are flowing in the reservoir, the production data are not ideal for deriving the gas-oil relative permeability curve. Nonetheless, the best match was obtained by using this set of permeability data and we continue using it in the rest of this study.

From the history-matching process, we have obtained base values for our simulation runs. In the next section, we will define the modeling strategy for our sensitivity study and the parameters considered.

\section{MODELING STRATEGY}

To fully understand the requirements for successful exploitation of low-permeability reservoirs, one should perform extensive simulation runs. Before any simulation, the objective function or response (e.g. cumulative oil production) should be defined and all impactful factors (those which are believed to affect the response, which might be as many as tens) should be determined. These factors usually require two to three levels (values) to cover all possible range of variations under different circumstances. An important question is that, in each simulation run, which parameters should be used in the sensitivities and which level(s) (high, medium and low) should be employed.

Design of Experiment (DOE) is a formal structured technique for studying any situation that involves a response that varies as a function of one or more independent variables (Mathews, 2005). DOE is specifically designed to address complex problems where more than one variable may affect the response and two or more variables may interact with each other. DOE replaces inferior methods such as the traditional method of studying the effect of One Variable at a Time (OVAT). Compared to DOE, the OVAT method is an inefficient use of resources and is incapable of detecting the presence of or quantifying interactions between variables (Mathews, 2005).

Application of DOE and Response Surface (RS) in reservoir engineering where an optimization problem, history match or uncertainty analysis is of interest has recently received considerable attention (such as works done by Zabalza-Mezghani et al., 2004; Feraille and Busby, 2009; Feraille and Marrel, 2012). DOE can considerably reduce the number of runs during a risk assessment problem which is an imperative concern for potentially expensive fluid flow simulations (Scheidt et al., 2007). Therefore, we use the DOE technique for determining the variables and their associated levels for each simulation run and the sequence in which these runs should be performed.

\section{SIMULATION RESPONSE AND VARIABLES}

The main objective function that we are interested in is the final oil recovery factor (recovery efficiency) of the reservoir. However, production from multi-fractured horizontal wells starts with relatively high rates followed by a rapid decline. Therefore, short-term recovery factors (recovery at the end of 5 years) and long-term recovery factors (recovery at the end of 20 years) will be considered separately as the responses. Seven factors which seem to affect the recovery in tight oil formations the most were chosen. These factors and their different levels are summarized in Table 3. Five parameters are assigned three levels and the two remaining ones get two levels. In the following, we provide a brief description of the response, selected factors and their levels and the rationale for these choices. 
TABLE 3

Factors considered for simulation runs

\begin{tabular}{|c|c|c|c|c|}
\hline Factor & Unit & Low & Medium & High \\
\hline A: number of wells & Number/section & 2 & 4 & 6 \\
\hline B: length of well & $\mathrm{Ft}$ & 1500 & 3000 & 4500 \\
\hline $\mathrm{C}$ : density of $\mathrm{HF}$ & Number of $\mathrm{HF} /(500 \mathrm{ft}$ well $)$ & 2 & - & 3 \\
\hline D: half-length of HF & $\mathrm{Ft}$ & 125 & 225 & 325 \\
\hline E: conductivity of HF & $\mathrm{md}-\mathrm{ft}$ & 250 & 750 & 1250 \\
\hline F: well operating BHP & Psi & 300 & 600 & 1200 \\
\hline G: completion method & $\mathrm{N} / \mathrm{A}$ & Open-hole ("1") & - & Cased-hole ("2") \\
\hline
\end{tabular}

\section{Recovery Factor (Response)}

The ultimate objective of any reservoir engineering design is to obtain the highest possible recovery from the reservoir, subject to economic viability of the design. However, we intentionally neglect the economic factors, as this is the focus of the second part of this study, which will be looking for the optimal design.

\section{Number of Wells per Section (Factor A)}

The number of wells and the spacing between them are important factors in management of recovery. As the number of wells increases, the cumulative drainage area of the wells increases as does the recovery efficiency. To simplify the problem, in all conducted simulations, the wells are aligned in the same direction and are evenly spaced in the reservoir section.

\section{Length of Well Lateral (Factor B)}

As the well length increases, more volume of the reservoir would participate in production leading to increased recovery. The minimum and maximum well lengths are $1500 \mathrm{ft}$ and $4500 \mathrm{ft}$, respectively.

\section{Density of Hydraulic Fractures (Factor C)}

The main goal of generating hydraulic fractures from the horizontal well is to increase the contacted area with the reservoir. It is reasonable to increase the number of fractures per well (to a point) in favor of obtaining higher recoveries. In this study, the hydraulic fractures will be evenly spaced along the well. Factor $\mathrm{C}$ controls the number of fractures along the well which can be calculated from Equation (2).

$$
\# H F / \text { Well }=\left\{\begin{array}{cc}
n+1 & ; C=2 \\
2 n+1 & ; C=3
\end{array}\right.
$$

where $n$ is the well length (B) $/ 500 \mathrm{ft}$. For instance, if a well is $3000 \mathrm{ft}$ in length, the number of fractures is 7 and 13 for $C$ equals to two and three, respectively.

\section{Half-Length of Hydraulic Fractures (Factor D)}

In the case of transverse hydraulic factures, increasing the fracture half-length also increases the contacted area for each horizontal well. In simulation runs, one of these values may be encountered: $125 \mathrm{ft}$ (short), $225 \mathrm{ft}$ (moderate) or $325 \mathrm{ft}$ (long).

\section{Conductivity of Hydraulic Fractures (Factor E)}

This factor is important in determining the dimensionless fracture conductivity parameter as given in Equation (3):

$$
F_{c d}=\frac{k_{f} \times w_{f}}{k \times x_{f}}
$$

where $k_{f} \times w_{f}$ is the conductivity of the hydraulic fracture, $k$ is the matrix permeability and $x_{f}$ is the fracture half-length. Considering a matrix permeability equal to $0.28 \mathrm{mD}$ the range of possible $F_{c d}$ in this study will be between 2.7 (for lowest fracture conductivity and highest fracture half-length) to 35.7 (for highest fracture conductivity and lowest fracture half-length). This range covers 
a spectrum of finite to almost infinite conductivity; i.e. $F_{c d}>20$ (Economides et al., 2002).

\section{Well Operating BHP (Factor F)}

BHP values closer to the oil bubble point pressure hinder the formation of two phase flow of oil and gas and keep oil effective permeability at higher values but restrict the overall flow rates. BHP values closer to atmospheric pressure on the other hand have a reverse effect. Thus, this factor may also have a two-sided effect on the recovery factors and needs to be considered.

\section{Completion Strategy (Factor G)}

In an "open-hole" completion, the whole length of the horizontal well + the hydraulic fractures contribute to the fluid flow while in the "cased-hole" method, the production only occurs through the hydraulic fractures to the well. This restricted flow path may adversely influence the productivity index of the well.

If OVAT technique is used to design the simulation runs, a total of $972\left(=3^{5} \times 2^{2}\right)$ runs will be required. However, if an "optimal design" scheme through DOE is used, far fewer runs will be required to obtain the same level of information. By an optimal design, we mean a design that is "best" with respect to some criterion.

There are several popular design optimality criteria like $A, D$ and $I$ just to name a few (Montgomery, 2007). In this study, we used the "D-optimal" design which is the most widely used and is a suitable choice for deterministic computer simulation models. However, it should be mentioned that "optimal design" is only one of the available algorithms in DOE and other methods such as "factorial design", "latin hypercube" or more sophisticated techniques have been used in dealing with demanding reservoir simulation runs (e.g., see Manceau et al., 2001; Feraille and Busby, 2009; Maschio et al., 2010; Ghomian et al., 2010).

\section{RESULTS AND DISCUSSION}

The collection of simulation runs and the order in which these runs performed are tabulated in Table 4 . As can be seen in this table, a total of 79 runs were carried out which is only $9 \%$ of the total runs required if the OVAT method were used. In each scenario, several factors may change simultaneously and acquire different levels. The design of the runs was performed using the ExpertDesign $^{\circledR}$ software (Stat-Ease, 2010). As can be seen in this table, no special pattern in the chosen factor levels from one run to the next can be recognized, thus the random nature of selections is honored.

Despite the significant difference in the time-span of the two model responses, as can be seen in Table 3, for the majority of the simulation runs, the recovery factor at the end of 20th year (long-term recovery) is not considerably higher than that at the end of the 5th year. Therefore, it is reasonable to analyze these two responses separately. According to these results, the short-term recovery factor ranges between $0.9 \%$ (Run 64) and $14.9 \%$ (Run 19) and between $2 \%$ and $18.7 \%$ for the long-term recovery for the same set of runs.

A half-normal probability plot is used to determine whether the entire set of factors and interaction effects are by coincidence (and, thus, shows no effect significantly different from zero) or whether some factors and/or interactions have significant effect. This is a plot of the absolute value of the effect estimates against their normal cumulative probabilities. Any factors or interactions whose observed effects are due to chance are expected to be randomly distributed around zero. These effects will tend to fall along a straight line called "line of no effect". The straight line on this plot always passes through the origin and should also pass close to the fiftieth percentile data value. The effects that might be significant have average values different from zero and are located a substantial distance away from the straight line that represents no effect (Montgomery, 2007).

Figure $3 \mathrm{a}$ displays the half-normal probability plot of the factors that might affect the short-term recovery factors in simulation runs. As this figure suggests, with the model properties used in this paper (Tab. 1), only 5 factors out of 7 have a significant effect on the recovery. The order of their significance is:

- the number of wells (factor A);

- the length of the well (factor B);

- operating BHP of the wells (factor F);

- half-length of hydraulic fracture ${ }^{(2)}$ (factor D);

- density of HF (factor C).

Interestingly, the conductivity of the fractures and the completion strategy in comparison with the other five factors have only a minor effect on the objective function (they are statistically insignificant). In other words, although increasing fracture conductivity and using the open-hole completion scheme may increase the recovery factor (which is the case for our simulation runs), investment in the other five factors possibly will yield better results. Figure $3 b$ is similar graph but for the long-term recovery factors. The same factors as in the short-term recovery cases have emerged as significant, except the

${ }^{2}$ The term "Hydraulic Fracture(s)" will be henceforth abbreviated as HF. 
TABLE 4

Simulation runs chosen based on the "d-optimal" design

\begin{tabular}{|c|c|c|c|c|c|c|c|c|c|}
\hline \multirow[t]{2}{*}{ Run No. } & \multicolumn{7}{|c|}{ Factor } & \multicolumn{2}{|c|}{ Response } \\
\hline & $\mathrm{A}$ & $\mathrm{B}$ & $\mathrm{C}$ & $\mathrm{D}$ & $\mathrm{E}$ & $\mathrm{F}$ & $G$ & $\begin{array}{l}\text { Rec. (\%) } \\
\text { short-term }\end{array}$ & $\begin{array}{l}\text { Rec. }(\%) \\
\text { long-term }\end{array}$ \\
\hline 1 & 4 & 4500 & 3 & 225 & 250 & 1200 & 1 & 5.2 & 7.8 \\
\hline 2 & 6 & 4500 & 2 & 225 & 1250 & 600 & 2 & 12.2 & 17.0 \\
\hline 3 & 4 & 4500 & 2 & 225 & 1250 & 1200 & 2 & 4.4 & 7.4 \\
\hline 4 & 2 & 3000 & 2 & 325 & 250 & 600 & 2 & 3.2 & 6.4 \\
\hline 5 & 6 & 1500 & 2 & 225 & 750 & 600 & 2 & 5.0 & 8.1 \\
\hline 6 & 2 & 1500 & 2 & 325 & 250 & 1200 & 1 & 1.1 & 2.3 \\
\hline 7 & 6 & 3000 & 2 & 325 & 250 & 300 & 1 & 10.5 & 14.3 \\
\hline 8 & 2 & 1500 & 3 & 225 & 1250 & 1200 & 1 & 1.2 & 2.3 \\
\hline 9 & 4 & 1500 & 3 & 225 & 750 & 600 & 1 & 4.0 & 6.8 \\
\hline 10 & 2 & 1500 & 3 & 225 & 750 & 300 & 1 & 2.3 & 4.5 \\
\hline 11 & 2 & 1500 & 3 & 225 & 250 & 1200 & 2 & 1.1 & 2.2 \\
\hline 12 & 6 & 1500 & 3 & 225 & 1250 & 600 & 1 & 5.6 & 7.9 \\
\hline 13 & 4 & 3000 & 2 & 125 & 250 & 1200 & 1 & 2.9 & 5.2 \\
\hline 14 & 2 & 3000 & 2 & 225 & 750 & 600 & 1 & 3.3 & 6.2 \\
\hline 15 & 4 & 1500 & 2 & 325 & 1250 & 300 & 1 & 5.1 & 8.1 \\
\hline 16 & 2 & 3000 & 3 & 125 & 1250 & 600 & 1 & 2.9 & 5.8 \\
\hline 17 & 6 & 4500 & 2 & 225 & 750 & 300 & 1 & 14.1 & 18.5 \\
\hline 18 & 4 & 1500 & 2 & 225 & 250 & 300 & 2 & 3.6 & 7.2 \\
\hline $19^{\dagger}$ & 6 & 4500 & 3 & 225 & 250 & 300 & 2 & 14.9 & 18.7 \\
\hline 20 & 4 & 1500 & 2 & 125 & 750 & 300 & 2 & 3.1 & 6.7 \\
\hline 21 & 6 & 4500 & 3 & 125 & 250 & 600 & 2 & 11.2 & 16.2 \\
\hline 22 & 2 & 4500 & 2 & 225 & 250 & 1200 & 2 & 2.0 & 4.1 \\
\hline 23 & 6 & 1500 & 3 & 325 & 1250 & 600 & 2 & 6.3 & 8.5 \\
\hline 24 & 2 & 3000 & 3 & 325 & 250 & 600 & 1 & 4.0 & 6.8 \\
\hline 25 & 6 & 4500 & 3 & 225 & 750 & 1200 & 2 & 7.4 & 9.1 \\
\hline 26 & 2 & 3000 & 3 & 325 & 750 & 300 & 2 & 5.0 & 8.2 \\
\hline 27 & 2 & 1500 & 2 & 225 & 1250 & 600 & 2 & 1.9 & 3.9 \\
\hline 28 & 6 & 3000 & 3 & 325 & 1250 & 1200 & 1 & 5.9 & 7.2 \\
\hline 29 & 4 & 3000 & 3 & 325 & 750 & 1200 & 2 & 4.6 & 6.4 \\
\hline 30 & 6 & 4500 & 3 & 125 & 1250 & 1200 & 2 & 6.1 & 8.7 \\
\hline 31 & 4 & 3000 & 3 & 225 & 250 & 600 & 2 & 6.7 & 10.7 \\
\hline 32 & 4 & 4500 & 2 & 225 & 250 & 600 & 1 & 8.5 & 14.1 \\
\hline 33 & 2 & 4500 & 3 & 125 & 750 & 300 & 2 & 4.6 & 8.7 \\
\hline 34 & 4 & 4500 & 3 & 325 & 1250 & 600 & 1 & 12.1 & 15.4 \\
\hline 35 & 4 & 4500 & 3 & 125 & 250 & 1200 & 2 & 4.2 & 7.1 \\
\hline 36 & 2 & 1500 & 2 & 325 & 250 & 300 & 2 & 2.1 & 4.5 \\
\hline 37 & 2 & 3000 & 2 & 125 & 1250 & 1200 & 2 & 1.3 & 2.8 \\
\hline 38 & 2 & 4500 & 2 & 325 & 750 & 300 & 1 & 6.0 & 10.0 \\
\hline
\end{tabular}

$\uparrow$ Highest short and long-term recovery.

\$ Lowest short and long-term recovery. 
TABLE 4 (continued)

\begin{tabular}{|c|c|c|c|c|c|c|c|c|c|}
\hline \multirow[t]{2}{*}{ Run No. } & \multicolumn{7}{|c|}{ Factor } & \multicolumn{2}{|c|}{ Response } \\
\hline & A & B & $\mathrm{C}$ & $\mathrm{D}$ & $\mathrm{E}$ & $\mathrm{F}$ & G & $\begin{array}{l}\text { Rec. (\%) } \\
\text { short-term }\end{array}$ & $\begin{array}{l}\text { Rec. }(\%) \\
\text { long-term }\end{array}$ \\
\hline 39 & 6 & 1500 & 3 & 225 & 1250 & 300 & 2 & 6.4 & 9.0 \\
\hline 40 & 6 & 3000 & 3 & 225 & 750 & 600 & 2 & 9.9 & 12.8 \\
\hline 41 & 6 & 1500 & 2 & 325 & 250 & 600 & 2 & 4.9 & 8.1 \\
\hline 42 & 4 & 3000 & 2 & 225 & 750 & 300 & 2 & 6.9 & 12.1 \\
\hline 43 & 4 & 3000 & 3 & 125 & 750 & 600 & 2 & 5.7 & 10.2 \\
\hline 44 & 4 & 3000 & 3 & 325 & 1250 & 300 & 2 & 9.7 & 13.2 \\
\hline 45 & 6 & 3000 & 2 & 125 & 250 & 600 & 1 & 7.7 & 12.1 \\
\hline 46 & 6 & 1500 & 2 & 125 & 750 & 300 & 1 & 5.1 & 8.5 \\
\hline 47 & 4 & 1500 & 2 & 325 & 750 & 600 & 1 & 4.4 & 7.2 \\
\hline 48 & 4 & 4500 & 2 & 125 & 250 & 300 & 1 & 8.4 & 15.2 \\
\hline 49 & 4 & 1500 & 3 & 225 & 250 & 300 & 1 & 4.3 & 7.4 \\
\hline 50 & 6 & 1500 & 2 & 125 & 1250 & 1200 & 2 & 2.0 & 3.9 \\
\hline 51 & 2 & 4500 & 2 & 225 & 1250 & 300 & 1 & 5.1 & 9.3 \\
\hline 52 & 4 & 4500 & 2 & 125 & 750 & 1200 & 1 & 4.2 & 7.1 \\
\hline 53 & 6 & 3000 & 2 & 325 & 750 & 1200 & 1 & 5.3 & 7.1 \\
\hline 54 & 2 & 1500 & 2 & 125 & 250 & 300 & 1 & 1.8 & 3.9 \\
\hline 55 & 6 & 1500 & 3 & 225 & 750 & 1200 & 1 & 3.0 & 4.4 \\
\hline 56 & 2 & 3000 & 2 & 125 & 1250 & 300 & 1 & 3.1 & 6.4 \\
\hline 57 & 6 & 4500 & 3 & 125 & 750 & 600 & 1 & 11.5 & 16.2 \\
\hline 58 & 6 & 1500 & 3 & 125 & 250 & 1200 & 1 & 2.5 & 4.1 \\
\hline 59 & 6 & 4500 & 2 & 125 & 750 & 300 & 2 & 10.9 & 18.0 \\
\hline 60 & 6 & 3000 & 2 & 225 & 250 & 1200 & 1 & 4.6 & 6.7 \\
\hline 61 & 2 & 4500 & 2 & 325 & 1250 & 1200 & 2 & 2.8 & 5.0 \\
\hline 62 & 6 & 4500 & 3 & 325 & 250 & 1200 & 2 & 7.5 & 9.2 \\
\hline 63 & 4 & 1500 & 2 & 325 & 1250 & 1200 & 2 & 2.3 & 3.9 \\
\hline 64 & 2 & 1500 & 3 & 125 & 750 & 1200 & 2 & 0.9 & 2.0 \\
\hline 65 & 4 & 1500 & 2 & 125 & 1250 & 600 & 2 & 2.8 & 6.0 \\
\hline 66 & 2 & 3000 & 3 & 225 & 1250 & 300 & 2 & 4.1 & 7.3 \\
\hline 67 & 2 & 4500 & 2 & 125 & 250 & 600 & 1 & 3.8 & 7.6 \\
\hline 68 & 6 & 3000 & 3 & 125 & 750 & 1200 & 1 & 4.4 & 6.5 \\
\hline 69 & 6 & 3000 & 3 & 125 & 250 & 300 & 2 & 8.9 & 13.5 \\
\hline 70 & 2 & 1500 & 2 & 225 & 750 & 1200 & 2 & 1.0 & 2.1 \\
\hline 71 & 6 & 3000 & 2 & 325 & 1250 & 300 & 2 & 11.0 & 15.0 \\
\hline 72 & 4 & 3000 & 2 & 225 & 1250 & 600 & 1 & 6.5 & 10.8 \\
\hline 73 & 4 & 1500 & 3 & 125 & 1250 & 1200 & 1 & 1.8 & 3.4 \\
\hline 74 & 6 & 4500 & 2 & 325 & 1250 & 600 & 1 & 14.1 & 16.9 \\
\hline 75 & 2 & 4500 & 3 & 325 & 750 & 600 & 2 & 6.2 & 9.7 \\
\hline 76 & 4 & 4500 & 3 & 325 & 750 & 300 & 2 & 13.3 & 17.4 \\
\hline 77 & 2 & 4500 & 3 & 125 & 250 & 1200 & 1 & 2.3 & 4.2 \\
\hline 78 & 4 & 1500 & 3 & 325 & 250 & 600 & 2 & 4.5 & 7.0 \\
\hline 79 & 2 & 4500 & 3 & 325 & 1250 & 300 & 1 & 7.0 & 10.9 \\
\hline
\end{tabular}



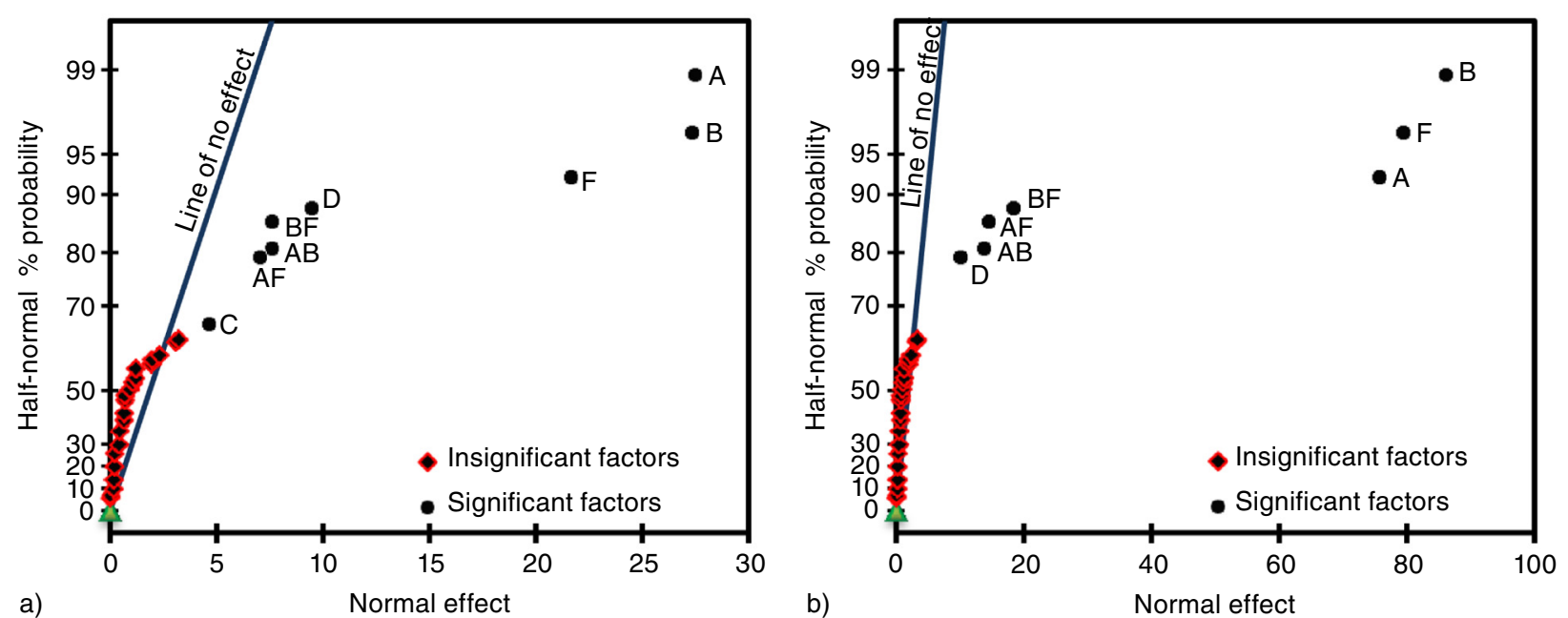

Figure 3

Half-normal probability plot of observed effect of factors and their interactions on a) short-term recovery factors and b) long-term recovery factor for reservoir model with absolute permeability equal to $0.28 \mathrm{mD}$.

density of HF (factor C). We will discuss the reasons for this difference later in the text.

In some situations, the difference in response between the levels of one factor is not the same at all levels of the other factors. When this occurs, there is interaction between the factors. For example in Figure 3, we see that interaction exists between $\mathrm{A}$ and $\mathrm{B}$, denoted as $\mathrm{AB}$, and this interaction is contributing to the recovery. However, factor D has no interaction with other factors. To clarify the interaction effect, consider Figure 4a in which recovery is plotted versus fracture half-length (factor D) at three different levels of factor A. The three depicted curves are approximately parallel to each other indicating that regardless of the level of A, increasing/decreasing the level of $\mathrm{D}$ from one level to the next one always causes the same amount of increase/decrease in recovery (similar slope for the curves). Since D has no interaction with any other factor, a similar plot will be obtained if the alternative factors (B, F, etc.) are used instead of $\mathrm{A}$. The general trend is similar; if the level of factor D increases the recovery factor will increase and vice versa. Conversely, we see in Figure $4 \mathrm{~b}$ that the curves describing the recovery factor versus the number of wells at different levels of $\mathrm{B}$ are non-linear; the amount of increase/decrease in the recovery factor depends on the changes in levels of both factors. For Figures $4 c$, d, similar comments can be made. Another possible conclusion from these figures is that increasing both the number and the length of the wells (Fig. 4a), increasing the number of wells and decreasing the BHP, increasing the well length and decreasing the BHP causes an increase in the achievable recovery factor. Therefore, more wells with longer laterals which are operating at lower BHP when stimulated with longer hydraulic fractures increases both short and long-term recovery.

It is worth looking at the effect of factors which were recognized as having an insignificant impact on primary recovery, namely fracture density (factor $\mathrm{C}$ ) for the longterm recovery efficiency, and fracture conductivity (factor E) and completion strategy (factor G) for both long-term and short-term efficiencies. Increasing the number of fractures per well, although improving the contacted area with the reservoir, causes the spacing between the fractures to reduce. Under constant BHP operation $\left(p_{w f}<p_{b}\right)$ this may accelerate the pressure depletion between the fractures and the formation of the two phase flow regimes in this region. This can adversely reduce the oil effective permeability. Nevertheless, the amount of reduction in the oil effective permeability is a function of the relative permeability characteristics and especially the oil relative permeability end points and critical gas saturation. If the critical gas saturation is so high that it takes a long time to reach that gas saturation between the fractures, then increasing the number of fractures (neglecting economic factors) would be favorable, otherwise there is not much benefit expected. However, since the low-permeability reservoirs should be produced under very low-BHP conditions, this critical value of the gas saturation between the fractures will pass soon after the start of the production and 
For: $B=1500 ; C=2 ; E=250 ; F=300 ; G=1$

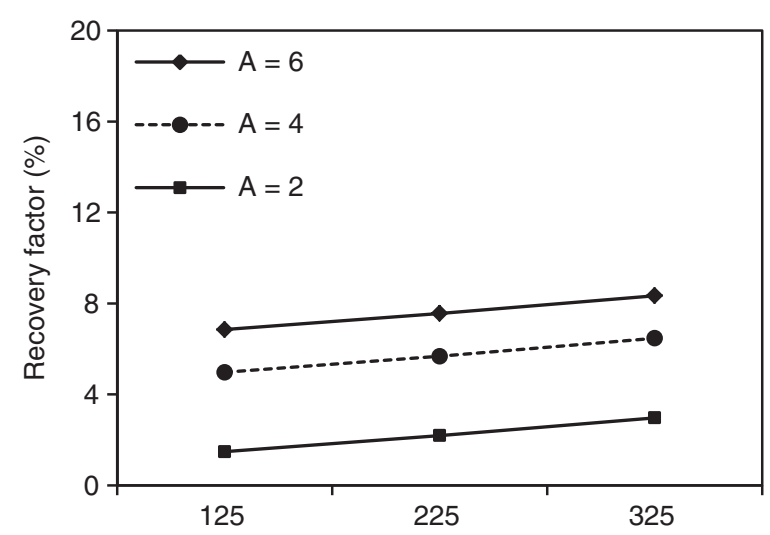

a)

For: $B=1500 ; C=3 ; D=325 ; E=250 ; G=1$

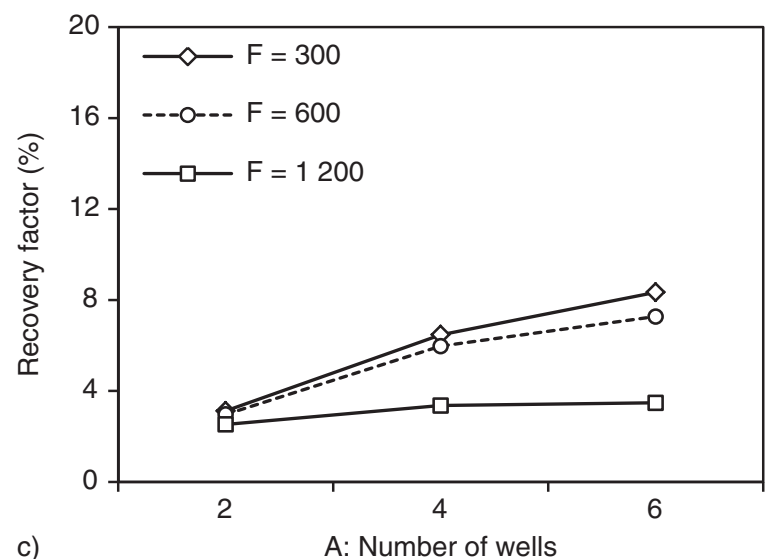

For: $\mathrm{C}=2 ; \mathrm{D}=125 ; \mathrm{E}=250 ; \mathrm{F}=300 ; \mathrm{G}=1$

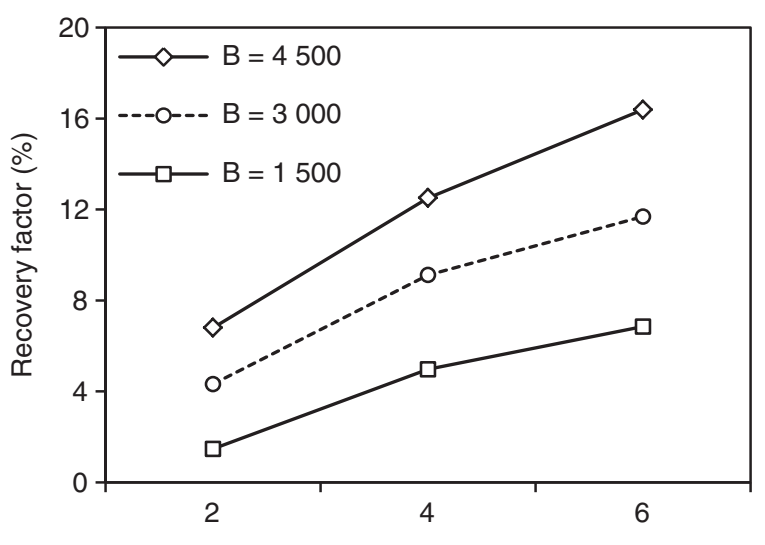

b)

A: Number of wells

For: $A=4 ; C=2 ; D=125 ; E=250 ; G=1$

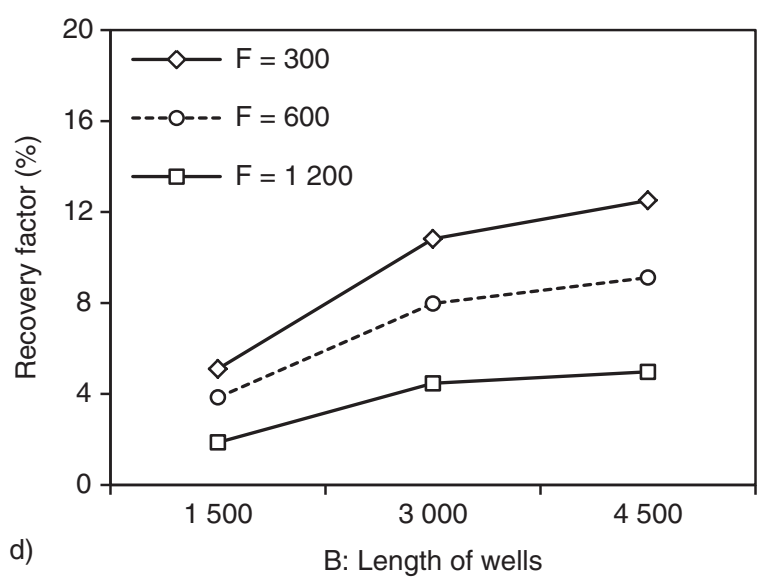

Figure 4

Effect interaction plot between different factors: a) $\mathrm{AD}$, no interaction case, b) $\mathrm{AB}, \mathrm{c}) \mathrm{AF}, \mathrm{d}) \mathrm{BF}$.

higher mobility of the gas with respect to oil hinders the sustainability of high oil production rates.

Figure 5a, b show the gas saturation distribution in the reservoir (top-view) after one year from start of production for two simulation runs which differ only in the number of fractures per well. The spacing between the fractures in Figure $5 \mathrm{a}$ is $500 \mathrm{ft}$ and in Figure $5 \mathrm{~b}$ is $250 \mathrm{ft}$. For the run with closer hydraulic-fracture spacing, the amount of the evolved gas saturation between fractures and also the extension of two phase oil-gas region is greater, both of which augment two phase flow interference. This in turn causes lower mobility to oil and hence reduces recovery efficiency. Figure $5 \mathrm{c}$ demonstrates that oil production rates from the model with larger number of fractures will produce oil at higher rates early on (short-term effect) but at later times the two-phase flow interference becomes important and productivity drops off (long-term effect). The recovery curves (Fig. 5d) are consistent with the oil production rates and the results from two half-normal probability plots. According to this figure, there is a statistically significant difference between the short-term recovery factors but this difference gradually diminishes over time. Therefore, there exists an optimum number for the fracture density which primarily depends on the reservoir characteristics and secondly on the economic concerns.

Our simulation results confirm that similar comments made for fracture spacing can be made for the effect of fracture conductivity, as this factor was also recognized as insignificant for recovery efficiency. Figure $6 \mathrm{a}$ 


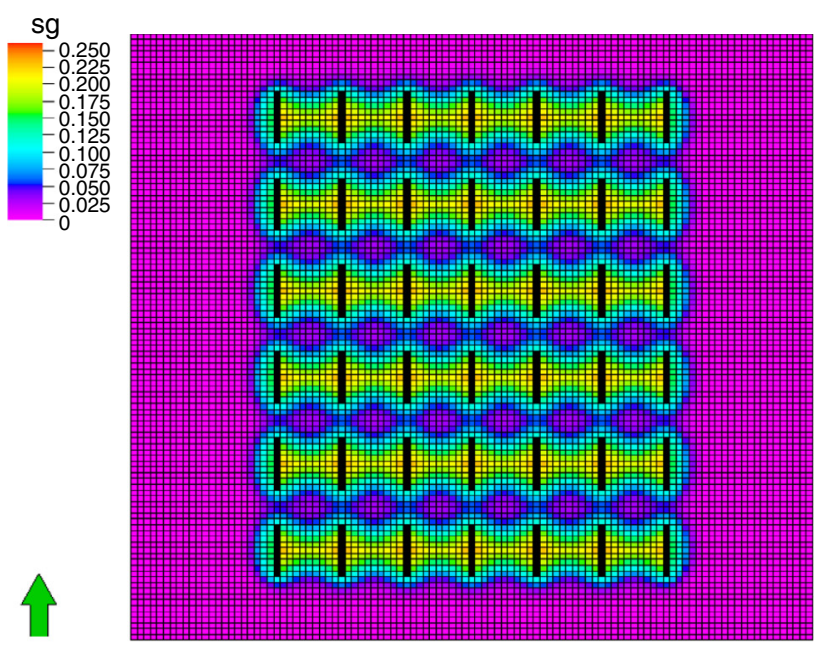

a)

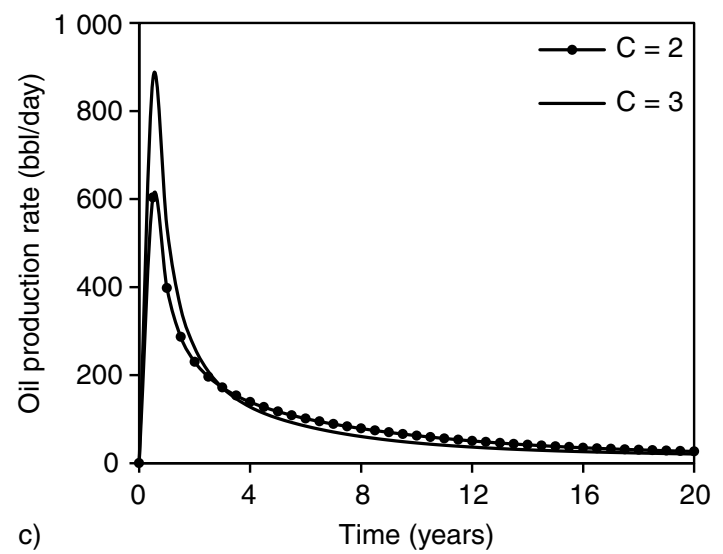

$\mathrm{sg}$

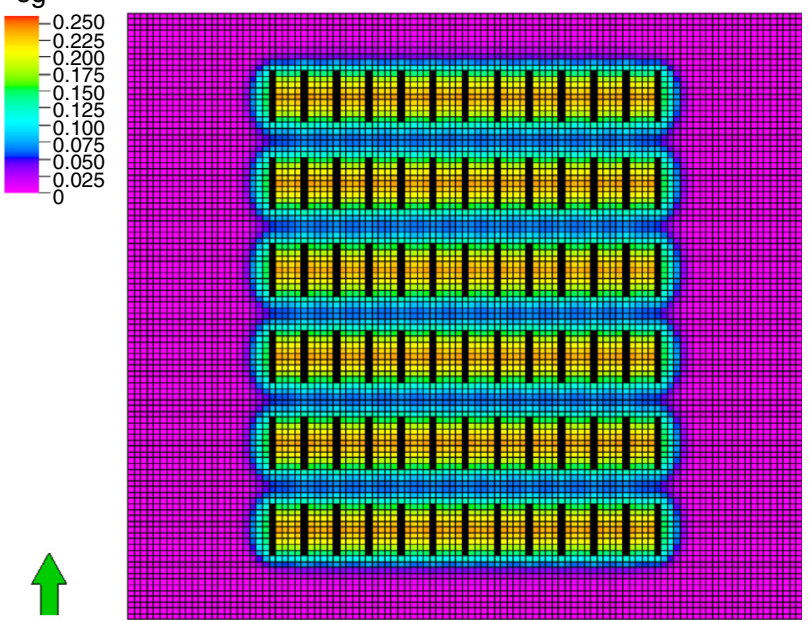

b)

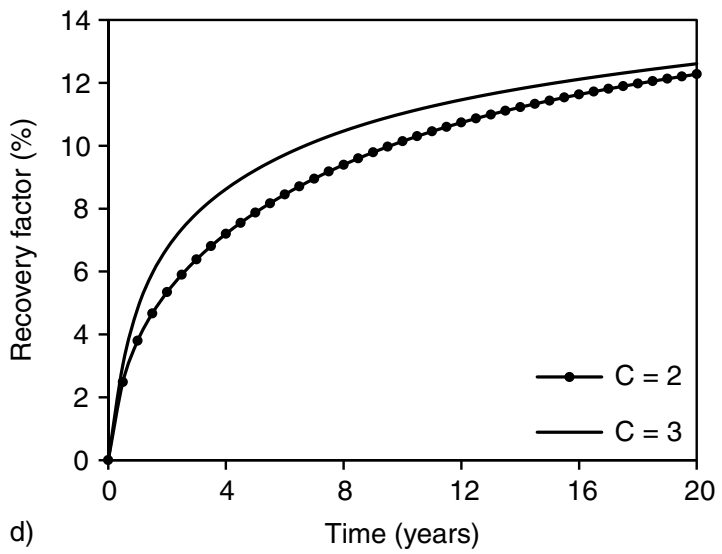

Figure 5

Gas saturation in two models with a) $\mathrm{C}=2$ and b) $\mathrm{C}=3$ one year after start of production; c,d) field oil production rates and the oil recovery factors for the models. Other parameters are as follow: $\mathrm{A}=6 ; \mathrm{B}=3,000 \mathrm{ft} ; \mathrm{D}=225 \mathrm{ft} ; \mathrm{E}=750 \mathrm{md}-\mathrm{ft} ; \mathrm{F}=300 \mathrm{psia}$.
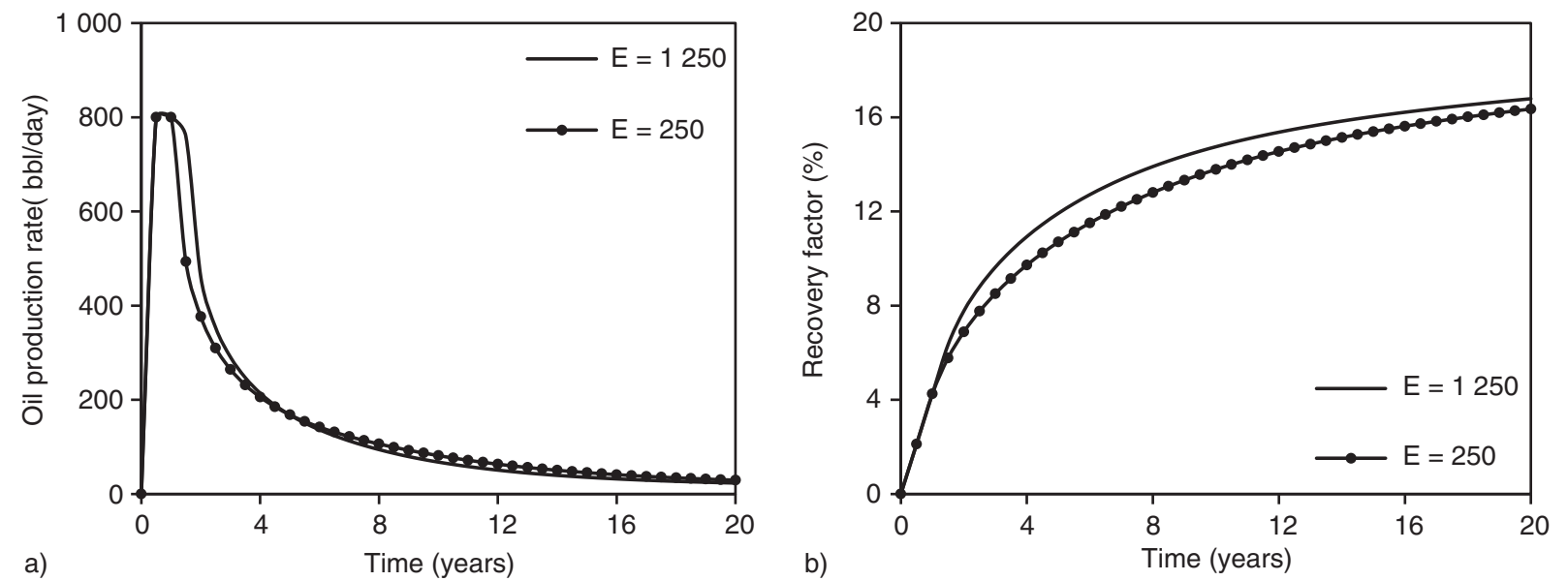

Figure 6

Field oil production rates a) and the oil recovery factors b) for the models with different levels of $\mathrm{E}$ factor; other parameters are as follow: $\mathrm{A}=4 ; \mathrm{B}=4500 \mathrm{ft} ; \mathrm{C}=2 ; \mathrm{D}=325 \mathrm{ft} ; \mathrm{F}=300 \mathrm{psia} ; \mathrm{G}=1$. 

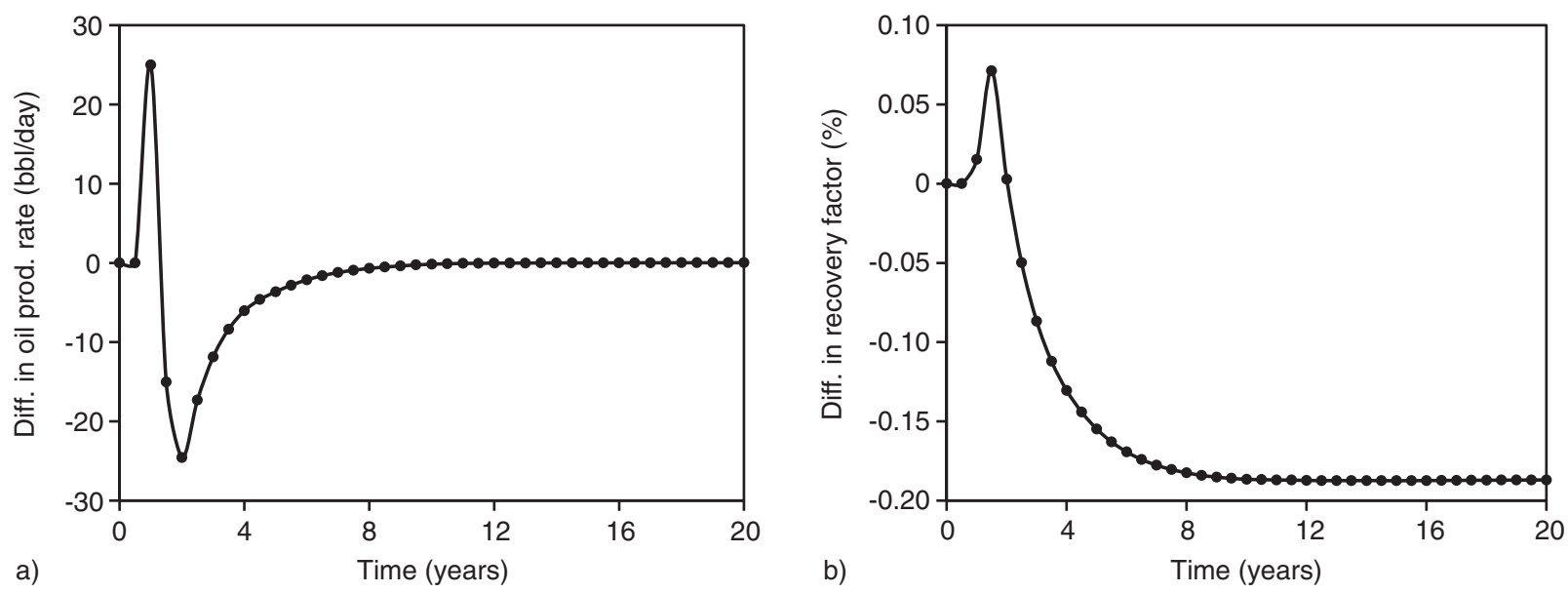

Figure 7

Difference in a) field oil production rates and b) the oil recovery factors for the models with different levels of $G$ factor (graph results $=$ "open-hole" results - "cased-hole" results); other parameters are as follow: $\mathrm{A}=6 ; \mathrm{B}=3000 \mathrm{ft} ; \mathrm{C}=3 ; \mathrm{D}=325 \mathrm{ft}$; $\mathrm{E}=750 \mathrm{md}-\mathrm{ft} ; \mathrm{F}=300$ psia.

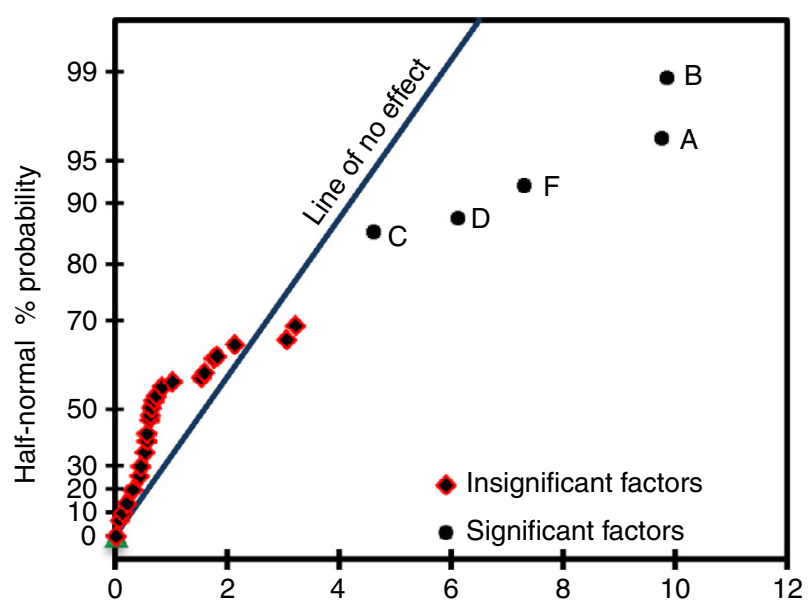

a)

Figure 8

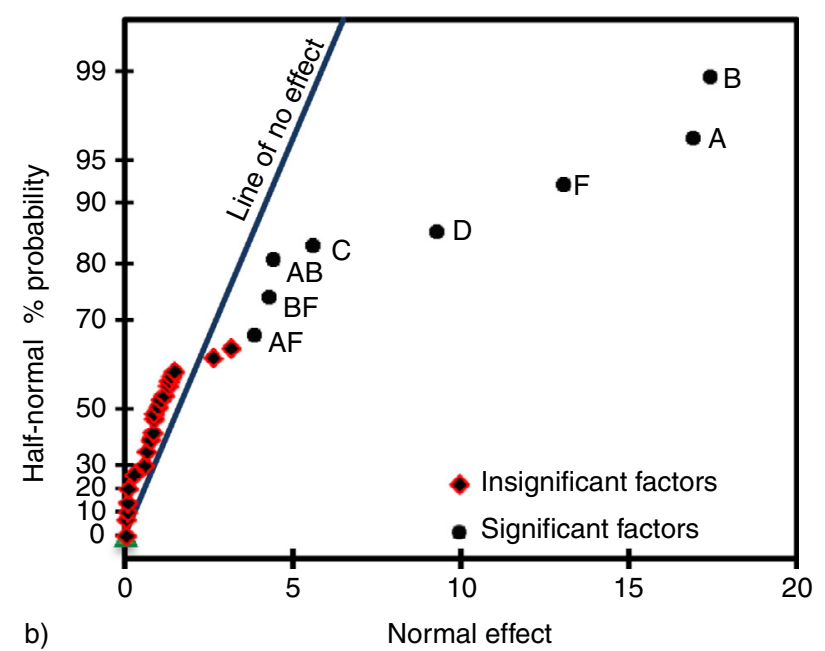

b)

Normal effect

Half-normal probability plot of observed effect of factors and their interactions on a) short-term recovery factors and b) long-term recovery factor for reservoir model with absolute permeability equal to $0.028 \mathrm{mD}$.

compares the oil production rate from two models which differ only in fracture conductivity. Figure $6 \mathrm{~b}$ demonstrates the corresponding recovery factors for the models. Embedding more conductive fractures will result in higher production rates earlier in the life of the project which might shorten the project pay-back period.

Finally, the difference in results for the open-hole and cased-hole methods (factor $\mathrm{G}$ ) is depicted in Figure 7 and confirms the outcome of the previous analysis which demonstrated that there is little difference between the two completion methods. The largest contribution to production occurs through the highly conductive fracture conduits and the contribution from other perforations along the horizontal well is of subtle importance. It should be also noted that a minor difference in the recovery factors between two models in Figure $7 \mathrm{~b}$ may arise from the numerical errors.

Since the conventional methods for measurement of permeability sometimes fail when applied to tighter formations, there is risk in the estimation of this property. Therefore, we repeated the analysis above but with absolute permeability reduced one order of magnitude 
(absolute permeability $=0.028 \mathrm{mD}$ ). The half-normal probability plot of the factor effects is given in Figure 8. It is interesting to note that once more the same significant factors appear on both graphs but now factor $\mathrm{C}$ is significant for short and long-term recovery efficiency (compare Fig. 8 and Fig. 3). Also comparing the two figures, we see that factor $C$ either does not appear as a significant factor or it sits very close (in comparison with other factors) to the "line of no effect". There is a good chance that if the reservoir properties change, particularly the relative permeability data, fracture density may be totally removed from the list of significant factors and hence it should be treated carefully and optimized for the formation under consideration. This result signifies the importance of accurate reservoir characterization for tight formations.

\section{CONCLUSION}

In this work, a systematic method for establishing the most important factors affecting primary recovery (short- and long-term) using multi-fractured horizontal wells is provided. The combination of Design of Experiment (DOE) and numerical simulation used in this work is superior to the One Variable at a Time approach (OVAT) used in many studies because a) fewer runs are required and $b$ ) the interaction between factors can be established and quantified.

For reservoir and fluid properties typical of the lowpermeability Pembina Cardium, the most important factors controlling primary recovery in order of significance are: the number of wells per section; the length of the well; operating BHP pressure of the wells. Fracture conductivity has a lesser effect on recovery factor but will impact early time production rates. Higher fracture density may accelerate oil production but also accelerates gas saturation build-up between fractures, which reduces oil mobility and impairs long term oil production. Further, whether or not fracture density has a significant impact on recovery depends on the combination of reservoir properties, particularly relative and absolute permeability, underpinning the need for careful reservoir characterization. The difference in long-term recovery factor due to completion method (open-hole versus cased-hole) appears to be insignificant.

Although we performed our sensitivity runs at two different matrix permeability levels, we recognize that there is also considerable uncertainty in relative permeability characteristics - we will perform our analysis using different relative permeability scenarios in the future.
In future work, reservoir heterogeneity and changes in relative permeability will be considered. Economic criteria will also be incorporated into the analysis. Finally, a similar approach will be used to establish critical factors controlling $\mathrm{CO}_{2}$-EOR in this tight oil play; $\mathrm{CO}_{2}$-EOR in this play is worthy of investigation because of not only the potential for increased of oil recovery but also the possibility for $\mathrm{CO}_{2}$ sequestration.

\section{ACKNOWLEDGMENTS}

A preliminary version of this paper was published as SPE 148995 and one-time copyright permission has been received through license number 3035390338406 from the society of petroleum engineers. This research was made possible by funding provided by ISEEE-NRCan (project title "Co-optimization of $\mathrm{CO}_{2}$ Sequestration and Oil Recovery in Tight Oil Formations"). Chris Clarkson would like to acknowledge Encana for support of his Chair position in Unconventional Gas at the University of Calgary, Department of Geosciences. He would also like to acknowledge the sponsors of Tight Oil Consortium (TOC), hosted at the University of Calgary. The authors would like to acknowledge ARC Resources for contributions of the Cardium well production.

\section{REFERENCES}

Adegbesan K.O., Costello J.P., Elsborg C.C., King D.A., Mills M., King R.W. (1996) Key Performance Drivers for Horizontal Wells Under Waterflood Operations in the Layered Pembina Cardium Reservoir, J. Can. Pet. Technol. 35, 8, 25-35, SPE paper 96-08-02.

Clarkson C.R., Pedersen P.K. (2010) Tight Oil Production Analysis: Adaptation of Existing Rate-Transient Analysis Techniques, Canadian Unconventional Resources \& International Petroleum Conference, Calgary, Alberta, Canada, 19-21 Oct., Paper CSUG/SPE 137352, DOI: 10.2118/137352-MS.

Clarkson C.R., Pedersen P.K. (2011) Production Analysis of Western Canadian Unconventional Light Oil Plays, Canadian Unconventional Resources Conference, Calgary, Alberta, Canada, 15-17 Nov., Paper CSUG/SPE 149005.

Economides M.J., Oligney R.E., Valkó P. (2002) Unified Fracture Design: Bridging the Gap between Theory and Practice, Orsa Press, Alvin, Texas.

Feraille M., Busby D. (2009) Uncertainty Management on a Reservoir Workflow, International Petroleum Technology Conference, Doha, Qatar, 7-9 Dec.

Feraille M., Marrel A. (2012) Prediction under Uncertainty on a Mature Field, Oil Gas Sci., Technol. - Rev. IFP Energies nouvelles 67, 2, 193-206.

Ghomian Y., Sepehrnoori K., Pope G.A. (2010) Efficient Investigation of Uncertainties in Flood Design Parameters 
for Coupled $\mathrm{CO}_{2}$ Sequestration and Enhanced Oil Recovery, SPE International Conference on $\mathrm{CO}_{2}$ Capture, Storage and Utilization, New Orleans, Louisiana, USA, 10-12 Nov., SPE Paper 139738.

Krause F.F., Collins H.N., Nelson D.A., Machemer S.D., French P.R. (1987) Multiscale Anatomy of a Reservoir: Geological Characterization of Pembina-Cardium Pool, West-central Alberta, Canada, AAPG Bull. 71, 1233-1260.

Manceau E., Mezghani M., Zabalza-Mezghani I., Roggero F. (2001) Combination Of Experimental Design and Joint Modeling Methods for Quantifying the Risk Associated with Deterministic and Stochastic Uncertainties - An Integrated Test Study, Annual Technical Conference and Exhibition, New Orleans, Louisiana, New-Orleans, USA, 30 Sept.-3 Oct., Paper SPE 71620-MS.

Maschio C., Viegas de Carvalho C.P., Schiozer D.J. (2010) A New Methodology to Reduce Uncertainties in Reservoir Simulation Models Using Observed Data and Sampling Techniques, J. Petrol. Sci. Eng. 72, 1, 110-119.

Mathews P. (2005) Design of Experiments with MINITAB, ASQ Quality Press, Milwaukee, Wisconsin.

Montgomery D.C. (2007) Design and Analysis of Experiments, seventh ed., John Wiley \& Sons Inc.

Pedersen K.S., Fredenslund A., Christensen P.L., Thomassen P. (1984) Viscosity of Crude Oils, Chem. Eng. Sci. 39, 6, 1011-1016.
Schlumberger (2010) Eclipse (version 2010.1) Reference Manual.

Schlumberger (2010) PVTi (version 2010.1) Reference Manual.

Shaoul J.R., Behr A., Mtchedlishvili G. (2007) Developing a Tool for 3D Reservoir Simulation of Hydraulically Fractured Wells, SPE Reserv. Eval. Eng. 10, 1, 50-59.

Stat-Ease Inc. (2010) Design-Expert (version 8.0.6) Reference Manual.

Scheidt C., Zabalza-Mezghani I., Feraille M., Collombier D. (2007) Toward a Reliable Quantification of Uncertainty on Production Forecasts: Adaptive Experimental Designs, Oil Gas Sci. Technol. 62, 2, 207-224.

Viau C., Nielsen K. (2010) Unconventional Oil Production in the Cardium Formation, East Pembina Area, Alberta, Canada, CSPG Core Conference, Calgary, Alberta, Canada, 16-17 Sept.

Zabalza-Mezghani I., Manceau E., Feraille M., Jourdan A. (2004) Uncertainty Management: From Geological Scenarios to Production Scheme Optimization, J. Petrol. Sci. Eng. 44, 1-2, 11-25. made or distributed for profit or commercial advantage and that copies bear this notice and the full citation on the first page. Copyrights for components of this work owned by others than IFP Energies nouvelles must be honored. Abstracting with credit is permitted. To copy otherwise, to republish, to post on servers, or to redistribute to lists, requires prior specific permission and/or a fee: Request permission from Information Mission, IFP Energies nouvelles, fax. + 331475270 96, or revueogst@ifpen.fr. 